\title{
A Randomized Trial on the Effect of Bone Tissue on Vibration-induced Muscle Strength Gain and Vibration-induced Reflex Muscle Activity
}

\author{
Muharrem Cidem ${ }^{1}$, İlhan Karacan ${ }^{1}$, Demirhan Diraçoğlu², Aysel Yıldız², Suat Hayri Küçük \\ Murat Uludağ $\breve{g}^{4}$, Kerem Gün ${ }^{4}$, Murat Özkaya ${ }^{1}$, Şafak Sahir Karamehmetoğlu ${ }^{4}$ \\ ${ }^{1}$ Department of Physical Medicine and Rehabilitation, Bağcılar Training and Research Hospital, İstanbul, Turkey
${ }^{2}$ Department of Physical Medicine and Rehabilitation, İstanbul University İstanbul Medical Faculty, İstanbul, Turkey
${ }^{3}$ Department of Biochemistry, Bağcclar Training and Research Hospital, İstanbul, Turkey
Department of Physical Medicine and Rehabilitation, İstanbul University Cerrahpaşa Medical Faculty, İstanbul, Turkey
}

Background: Whole-body vibration (WBV) induces reflex muscle activity and leads to increased muscle strength. However, little is known about the physiological mechanisms underlying the effects of whole-body vibration on muscular performance. Tonic vibration reflex is the most commonly cited mechanism to explain the effects of whole-body vibration on muscular performance, although there is no conclusive evidence that tonic vibration reflex occurs. The bone myoregulation reflex is another neurological mechanism used to explain the effects of vibration on muscular performance. Bone myoregulation reflex is defined as a reflex mechanism in which osteocytes exposed to cyclic mechanical loading induce muscle activity.

Aims: The aim of this study was to assess whether bone tissue affected vibration-induced reflex muscle activity and vibration-induced muscle strength gain.

Study Design: A prospective, randomised, controlled, double-blind, parallel-group clinical trial.

Methods: Thirty-four participants were randomised into two groups. High-magnitude whole-body vibration was applied in the exercise group, whereas low-magnitude whole-body vibration exercises were applied in the control group throughout 20 sessions. Hip bone mineral density, isokinetic muscle strength, and plasma sclerostin levels were measured. The surface electromyography data were processed to obtain the Root Mean Squares, which were normalised by maximal voluntarily contraction.

Results: In the exercise group, muscle strength increased in the right and left knee flexors $(23.9 \%, \mathrm{p}=0.004$ and $27.5 \%, \mathrm{p}<0.0001$, respectively). However, no significant change was observed in the knee extensor muscle strength. There was no significant change in the knee muscle strength in the control group. The vibration-induced corrected Root Mean Squares of the semitendinosus muscle was decreased by 2.8 times $(\mathrm{p}=0.005)$ in the exercise group, whereas there was no change in the control group. Sclerostin index was decreased by $15.2 \%(\mathrm{p}=0.031)$ in the exercise group and increased by $20.8 \%(\mathrm{p}=0.028)$ in the control group. A change in the sclerostin index was an important predictor of a change in the vibration-induced normalised Root Mean Square of the semitendinosus muscle $(\mathrm{R} 2=0.7, \mathrm{p}=0.0001)$. Femoral neck bone mineral density was an important predictor of muscle strength gain $(\mathrm{R} 2=0.26, \mathrm{p}=0.035)$. Conclusion: This study indicates that bone tissue may have an effect on vibration-induced muscle strength gain and vibration-induced reflex muscle activity.

Trial registration: ClinicalTrials.gov: NCT01310348.

(Balkan Med J 2014;31:11-22).

Key Words: Bone mineral density, electromyography, muscle training, sclerostin, tonic vibration reflex
Whole-body vibration (WBV), as a method of exercise training, is becoming increasingly popular in physical therapy, rehabilitation, and professional sports, and is increasingly used in beauty and wellness applications due to its beneficial effects on the neuromusculoskeletal system. These benefits include improved strength, power, flexibility, jump height, and balance (1-4).

However, little is known about the physiological mechanisms underlying the effects of WBV on muscular perfor- mance, although the presence of reflex muscle activity during WBV has been shown $(4,5)$. Tonic vibration reflex (TVR) is the most commonly cited mechanism to explain the effects of WBV on muscular performance, although there is no conclusive evidence that tonic vibration reflex (TVR) occurs (4-6). Studies have reported that direct vibration applied to a muscle or tendon stimulates muscle spindles, thereby causing a TVR to occur. As highlighted by these studies, muscle spindle 
discharges are sent to the spinal cord through Group Ia afferents during muscle or tendon vibration. There, they activate motoneurons that cause the muscle to contract $(2,3,6$, 7). However, it has been reported that the sensitivity of the muscle spindle decreases or does not increase, and that presynaptic inhibition occurs in Group Ia afferent fibres with vibration (6, 8-14).

The bone myoregulation reflex (BMR) is another neurological mechanism used to explain the effects of vibration on muscular performance. BMR is a reflex mechanism in which osteocytes exposed to cyclic mechanical loading induce muscle activity. Osteocytes embedded in the bone matrix are interconnected by numerous dendritic processes, forming a wide, mechanosensitive cellular network. Osteocytes exposed to cyclic mechanical loading send mechanical input signals to the central nervous system, influencing the neuronal regulation of muscle activity $(11,15,16)$. This study was designed to analyse the role of BMR in the muscular response during WBV.

WBV induces reflex muscle activity and leads to increased muscle strength (1-5). We hypothesised that bone tissue plays an important role in the effect of WBV on reflex muscle activity and muscle strength gain. The aim of this study was to assess whether bone tissue affected vibration-induced muscle strength gain and vibration-induced reflex muscle activity.

\section{MATERIAL AND METHODS}

\section{Subjects}

Ethical approval was obtained from the Institutional Review Board (Approval Number, 2011 / 392-461). All participants were volunteers and provided written informed consent. Sixty-seven participants who voluntarily agreed to participate in this study were assessed for eligibility. Informed consent was obtained from 39 people who met the inclusion and exclusion criteria (Table 1). Participants were randomised into two groups, the exercise (EX) and control (CON) groups. One investigator was involved in the randomisation process. Coin flipping was used for the randomisation procedure. Two participants in the EX group and three participants in the $\mathrm{CON}$ group did not receive allocation intervention (Figure 2). The mean age of the participants was 31.6 \pm 5.6 years in the EX group $(n=17)$ and $30.0 \pm 5.8$ years in the CON group $(n=17)(p=0.407)$; the mean body mass index (BMI) was $23.7 \pm 2.4 \mathrm{~kg} . \mathrm{m}-2$ and $23.9 \pm 2.5 \mathrm{~kg} . \mathrm{m}^{-2}(\mathrm{p}=0.879)$, respectively.

\section{Procedures}

The current study was a prospective, randomised, controlled, double-blind, parallel-group clinical trial. WBV-induced muscle strength gain was measured using an isokinetic dynamometer. WBV-induced reflex muscle activity was evaluated using surface electromyography (SEMG). To examine the effects of bone tissue on vibration-induced muscular performance, hip bone mineral density (BMD) and plasma sclerostin levels were measured.

Sclerostin, a mechanosensitive protein, is produced almost exclusively by osteocytes. Its expression in adult bone is regulated by me-
TABLE 1. Inclusion and exclusion criteria
Inclusion Criteria
1. Premenopausal women 20-40 years of age,
2. Good health
3. Right hand dominant women
Exclusion Criteria
1. Pregnancy, menstrual irregularities
2. Postural abnormalities (e.g., scoliosis, kyphosis)
3. Cardiovascular, dermatological, abdominal, urinary, gynaecological, neurological, musculoskeletal, endocrine, or other disease
4. Medication that could affect the neuromusculoskeletal system
5. Obesity (body mass index $>30 \mathrm{~kg} \cdot \mathrm{m}-2$ or body weight $>80 \mathrm{~kg}$ )
6. Vertigo
7. Cognitive dysfunction
8. Professional/regular sports activity
9. Participation in heavy work

chanical strain (17-19). WBV can cause changes in plasma sclerostin levels in adult women (20). Plasma sclerostin levels indicate osteocyte activity (21). Osteocytes, the primary mechanosensors in bone, are the 'receptors' of BMR (15). Thus, changes in plasma sclerostin levels with WBV can be used as a tool to demonstrate changes in osteocyte activity following WBV.

To examine the effects of bone tissue on vibration-induced muscular performance, hip BMD was used as a bone-related second variable. A previous study reported that forearm BMD was an important predictor of wrist muscle strength gain (15).

Hip BMD was measured once prior to the trial. SEMG analyses, muscle strength measurements, and plasma sclerostin level measurements were done prior to the 20 -session exercise program (pre-trial measurements) and within 3 days after completion of the 20-session exercise program (post-trial measurements) in both groups. For testing, high-magnitude vibration was applied in all participants (Figure 1). All measurements were done blindly.

For exercise, high-magnitude vibration was applied in the EX group, and low-magnitude vibration was applied in the CON group throughout the 20 sessions. Data collected from the EX group were compared with those from the CON group to determine the effect of WBV exercise on changes in muscle strength and vibration-induced reflex muscle activity.

\section{Whole-body vibration}

The participants were barefoot, and no sponge or foam was placed between the vibration platform and their feet. Participants stood upright with their knees locked during WBV. This position was used during WBV because it exposed the lower-extremity bones to maximum mechanical load while preventing stretching of the extrafusal and intrafusal muscle fibres in the knee flexor and extensor muscles. In most studies of WBV, vibration has generally been applied in a squatting or semi-squatting position; however, intramuscular tension is high in such positions $(6,22)$.

Maintaining static balance in a standing position may be difficult during WBV, and muscle contractions in the lower leg may occur to maintain the balance. To prevent such instability, two precautions were taken. First, the base of support (distance between the heels) was adjusted. Two white strips were pasted $30 \mathrm{~cm}$ apart on the vibra- 


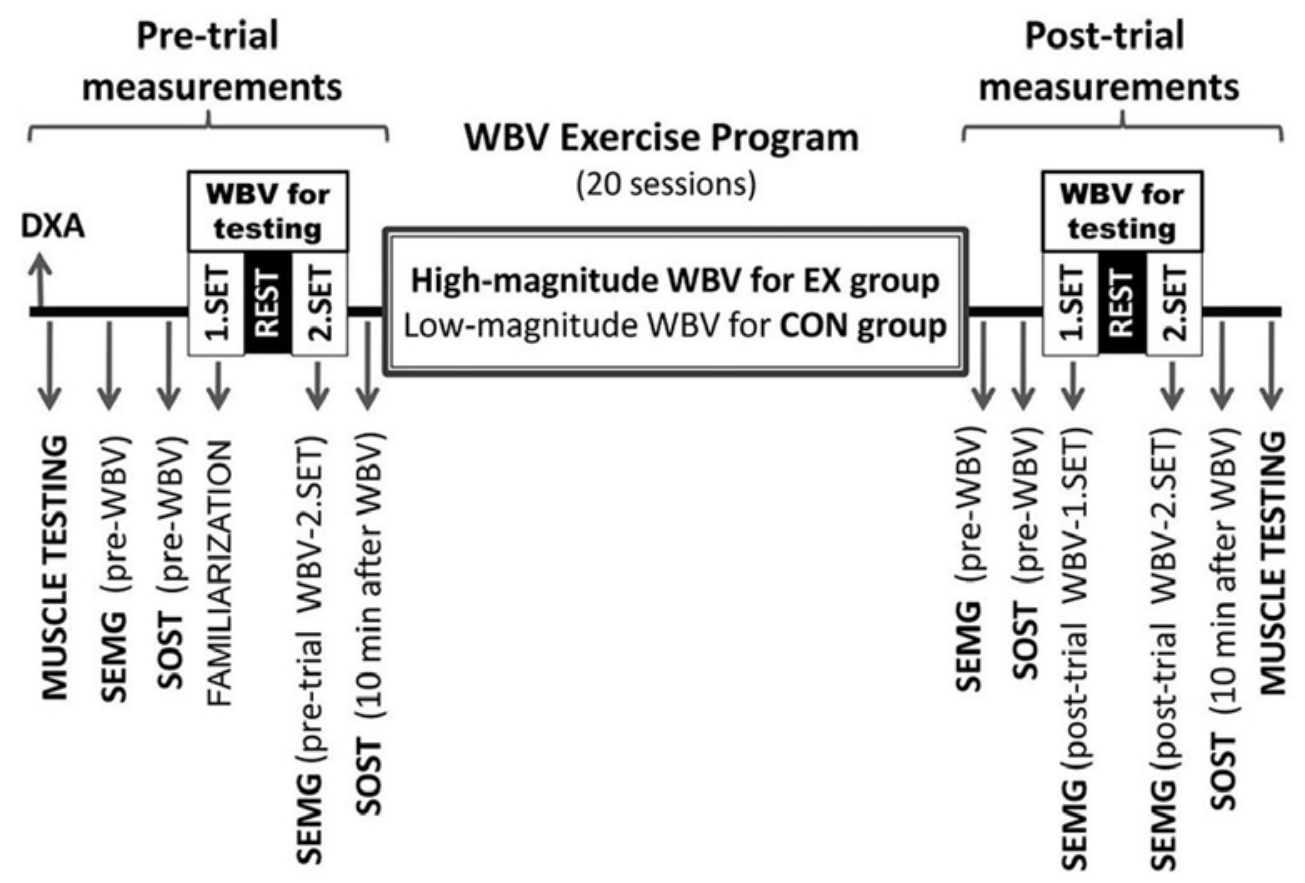

FIG. 1. Experimental procedures

tion platform, and participants were asked to place their feet on the two white strips. As a second precaution, participants were asked to hold the handles of the WBV equipment (Figure 3). WBV was performed for the dual purpose of testing and exercise.

\section{Whole-body vibration for testing}

For the plasma sclerostin level and vibration-induced reflex muscle activity measurements, WBV was applied for testing purposes by using POWER PLATE ${ }^{\circledR}$ (POWER PLATE ${ }^{\circledR}$ Pro5; PowerPlate International, Amsterdam, The Netherlands). For pre-trial measurements, two sets of WBV with low $(2 \mathrm{~mm})$ amplitude at $40 \mathrm{~Hz}$ for $30 \mathrm{~s}$ for each set were applied. For the post-trial measurements, low-amplitude WBV was applied at $40 \mathrm{~Hz}$ for $30 \mathrm{~s}$ in the first set and highamplitude (4 mm) WBV was applied at $40 \mathrm{~Hz}$ for $30 \mathrm{~s}$ in the second set. A rest period of $10 \mathrm{~s}$ was provided between sets.

\section{Whole-body vibration for exercise}

For exercise, POWER PLATE ${ }^{\circledR}$ Pro5 was used to apply a highmagnitude vibration (2.7 and $5.1 \mathrm{~g}$ acceleration) in the EX group, and VIBRO10000 ${ }^{\circledR}$ (VIBRO10000; Luster International Trading, Zhejiang, China) was used to apply a low-magnitude vibration $(0.1 \mathrm{~g}$ acceleration) in the CON group (Figure 3). WBV exercises were applied regularly in both groups through 20 sessions ( 5 days per week for 4 weeks). All participants completed all exercise sessions.

In the first session, two sets of WBV (2-mm amplitude, $40 \mathrm{~Hz}, 2.7$ g, $30 \mathrm{~s}$ per set) were applied in the EX group. The intensity of the exercises was progressively increased. In the last session, five sets of WBV (4-mm amplitude, $40 \mathrm{~Hz}, 5.1 \mathrm{~g}, 30 \mathrm{~s}$ per set) were applied.
There was a rest period of $10 \mathrm{~s}$ between sets. One set of vibrations ( 4 $\mathrm{Hz}, 7 \mathrm{~mm}$ amplitude, $0.1 \mathrm{~g}$ ) was applied in the CON group per session. The duration of the vibration for the first seven sessions was 1 min. For the subsequent seven sessions, the duration was $2 \mathrm{~min}$, and the duration for the last six sessions was $3 \mathrm{~min}$.

\section{Isokinetic muscle torque}

Isokinetic muscle torque was measured with the BIODEX ${ }^{\circledR}$ (Biodex System 3 PRO Multijoint System Biodex Medical, Inc., Shirley, NY, USA). The muscles tested included the right and left knee flexors and extensors. The measurements were first performed in the right extremity followed by the left extremity in each participant. Participants were seated with the knee and hip at a $90^{\circ}$ angle, and the axis of rotation of the dynamometer was aligned with the lateral femoral epicondyle. To minimise movement and the contribution of other muscles, the participants were strapped to the dynamometer by placing belts around the waist, pelvis, and thigh. Participants were instructed to pull and push as hard as possible throughout the entire range of motion. Prior to testing, the participants warmed up their lower extremity muscles. The knee muscles were tested at three different speeds $\left(60,180\right.$, and $\left.240^{\circ} . \mathrm{s}^{-1}\right)$. A rest period of 1 min was applied between testing velocities to reduce the likelihood of fatigue. During the test, participants were encouraged to perform maximal muscle performance by standardised auditory and visual feedback at every repetition. The isokinetic dynamometer reported the data as mean peak torque. The peak torque, measured in Newton meters (N.m), was normalised to body weight. All measurements were performed by the same laboratory assistant. 


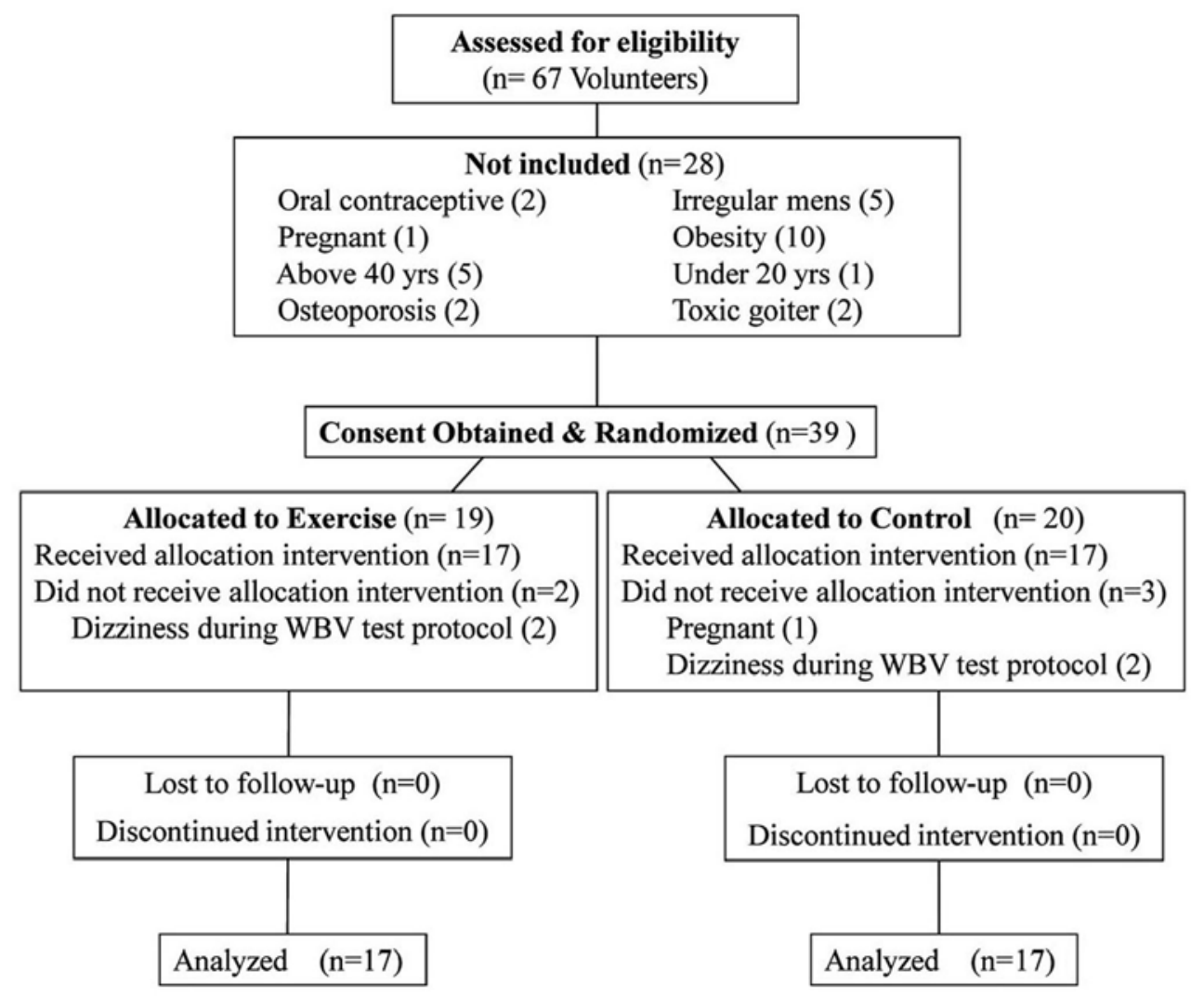

FIG. 2. Flow chart of participants considered for inclusion

\section{Surface electromyography}

SEMG recordings (POWERLAB ${ }^{\circledR}$ data acquisition system; ADInstruments Co, Oxford, United Kingdom) were obtained from the right rectus femoris and semitendinosus muscles. SEMG was sampled at a frequency of $2 \mathrm{kHz}$.

Self-adhesive, disposable, $\mathrm{Ag} / \mathrm{AgCl}$ disc electrodes $10 \mathrm{~mm}$ in diameter (KENDALL ${ }^{\circledR}$ Arbo; Coviden; Massachusetts, USA) were used. Prior to electrode placement, the skin was shaved, lightly abraded, and cleaned with alcohol wipes. Electrodes were placed on the rectus femoris and semitendinosus in accordance with the SENIAM guide (23). To prevent the snap end of the cable from swinging, it was fixed to the body. In all cases, electrodes were placed by the same laboratory technician.

SEMG recordings were obtained in three positions: while participants performed maximal voluntary contraction (MVC) for $5 \mathrm{~s}$ against manual resistance in a lying position; in a quiet standing position; and during WBV. While SEMG recordings were being obtained in a quiet standing position and during $\mathrm{WBV}$, participants were asked to relax and not to make voluntary contractions in their lower extremity muscles. For that purpose, participants were given relaxation training while in the quiet standing position. This training was provided with verbal feedback given by the researcher who monitored the SEMG recordings from the screen. The same verbal feedback was given during WBV to preserve the relaxed state of the partici- pants. During pre-trial measurements, the first set of WBV was applied to familiarise participants with the process. The second set was applied to collect SEMG data (Pre-trial 2.set data). During post-trial measurements, both sets of WBV were applied to collect SEMG data (Post-trial 1.set and Post-trial 2.set data).

The SEMG data were processed offline by a computer. All SEMG analyses were conducted using LABCHART $^{\circledR}$ Software Version V7.3.3 (POWERLAB ${ }^{\circledR}$ system ADInstruments, Oxford, United Kingdom). All SEMG recordings and analyses were conducted by the same researcher. The first and last $1.5 \mathrm{~s}$ of the exercise data were discarded to eliminate vibration onset and finish effects (artifacts), and the remaining $27 \mathrm{~s}$ were further analysed.

Myoelectrical activity measurements recorded via SEMG could be affected by motion artifacts $(6,24,25)$. Such artifacts can be eliminated using appropriate series of notch filters and full-wave rectification without losing valuable information on the motor unit response to vibration in SEMG data (26). In this study, the raw SEMG signals were first band pass-filtered between 20 and $1000 \mathrm{~Hz}$. Next, vibration-induced motion artifacts were removed by filtering out the sharp peaks in the signal spectrum corresponding to the vibration frequency $(40 \mathrm{~Hz})$ and the harmonics of the vibration frequency (80, 120 , and $160 \mathrm{~Hz}$ ) by notch filters. After filtering, the SEMG signal was rectified to reveal information regarding the discharge rates of motor units (Figure 4). 

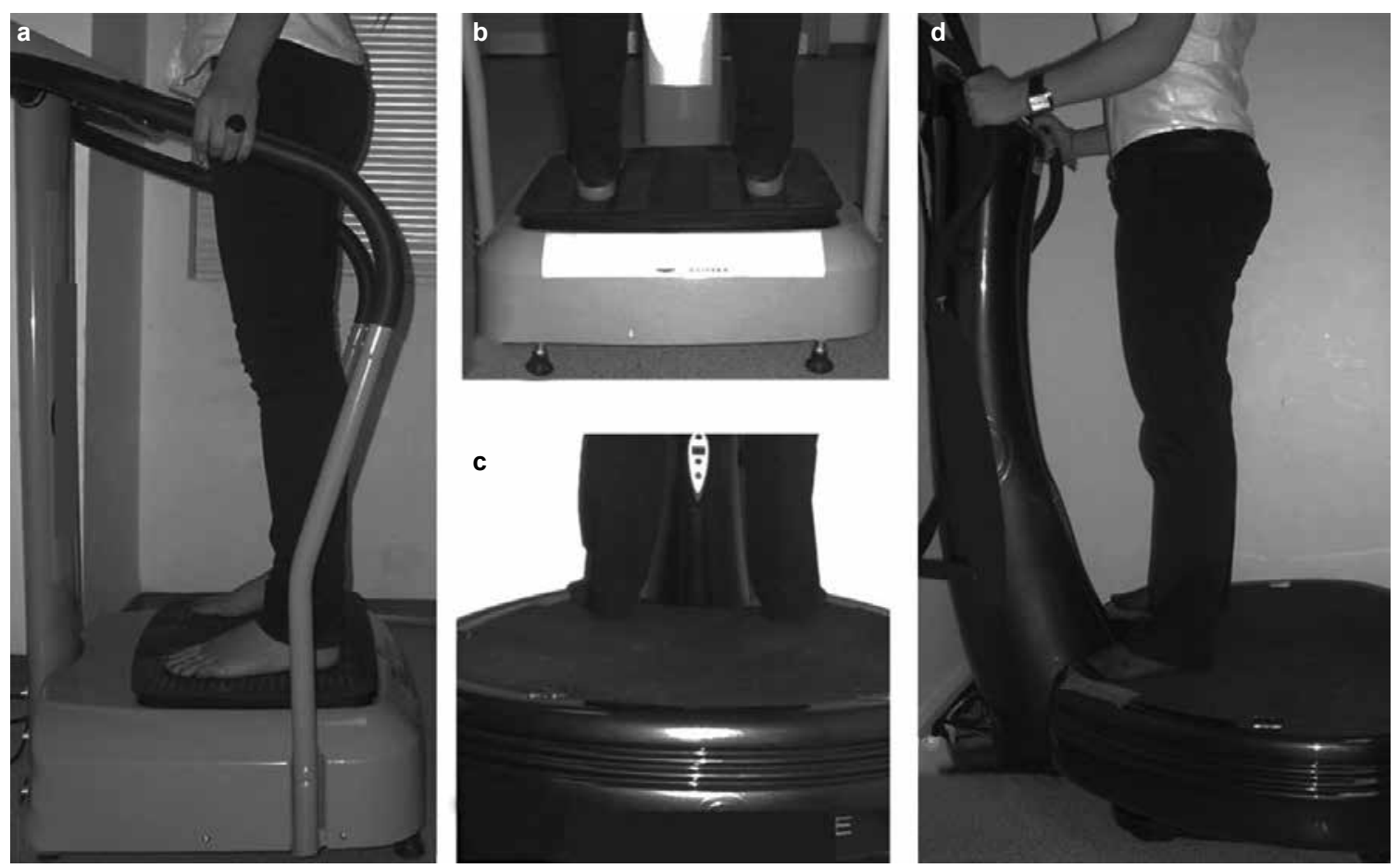

FIG. 3. a-d. Posture of the participants and WBV devices used in this study. A side-alternating WBV device used for the CON group generated vibrations by oscillating along the axis (adjustable gravity force: $0.1-33 \mathrm{~g})(\mathrm{a}, \mathrm{b})$. A synchronous WBV device was used for the EX group; the whole plate oscillated with a linear movement upward and downward (adjustable gravity force: 1.8 - $6.3 \mathrm{~g})(\mathrm{c}, \mathrm{d}$ )

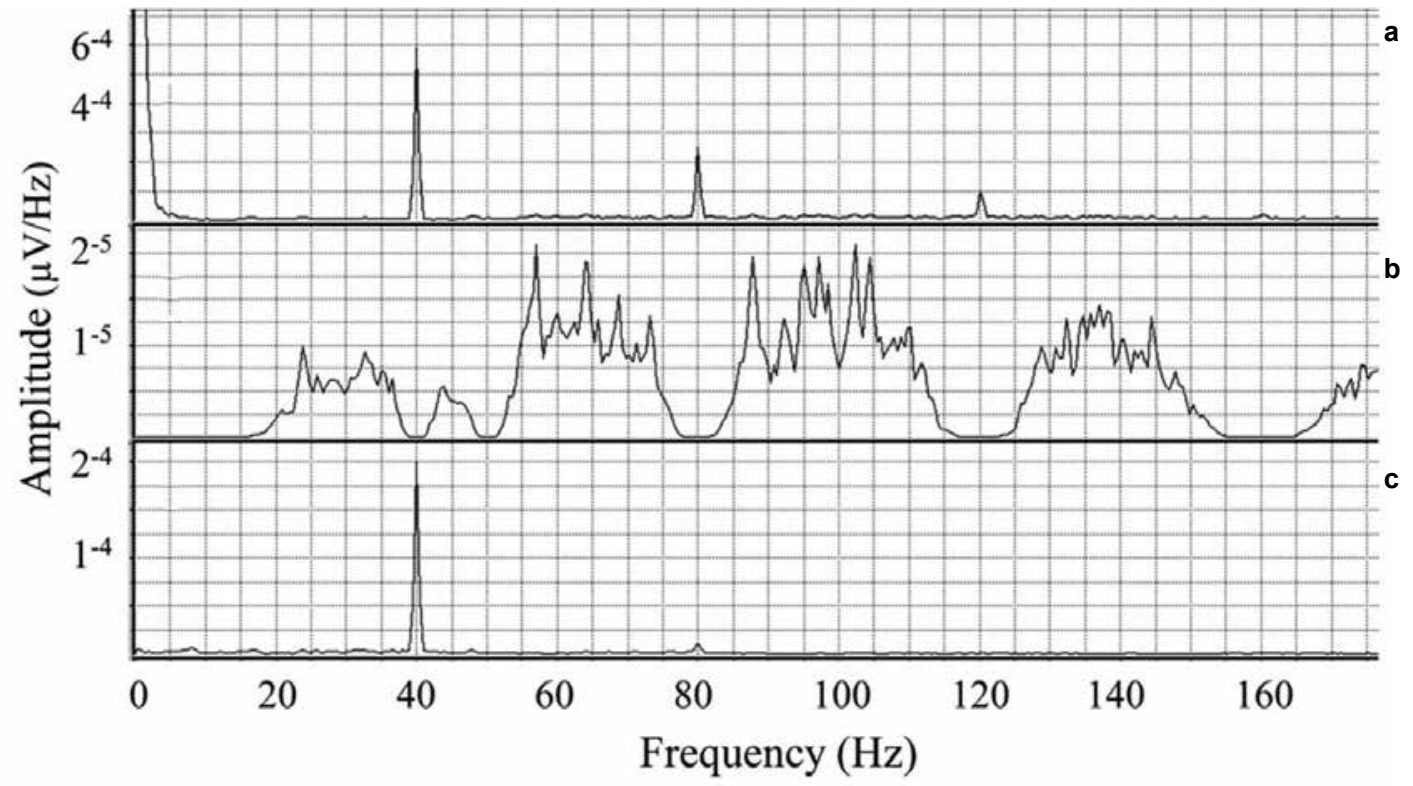

FIG. 4. a-c. Frequency spectrograms of SEMG signals recorded during WBV. Unprocessed SEMG signal (a). Filtered SEMG signal and elimination of artifacts (b). Rectified SEMG signals showing a prominent peak at the vibration frequency $(40 \mathrm{~Hz})$ due to synchronisation (c)

The Root Mean Square (RMS) values were calculated from the filtered SEMG signal. The RMS of the SEMG voltage was normalised to MVC, and was expressed as RMSMVC. The RMS amplitude calculated from the recordings measured during WBV was defined as vibration-induced RMS. Vibration-induced RMS was normalised to MVC, and was expressed as as Normalized Vibration-Induced (NVI) - RMS. The NVI - RMS was used as an indicator of the reflex muscle response to vibration. 
Pre-trial NVI - RMS and post-trial NVI - RMS were calculated. To standardise the NVI - RMS changes that occurred after the trial, the following formulas were applied:

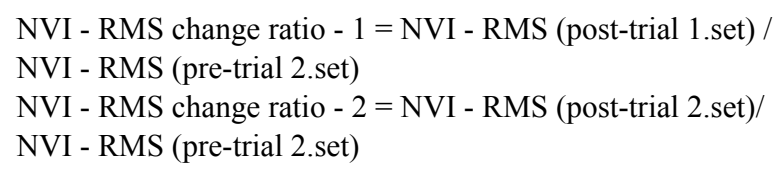

Fast Fourier transform (FFT) analysis was used to determine the frequency components of the recorded signals. The power spectral analyses conducted were Hanning-windowed. The FFT length was set to 4096 points.

Co-contraction of antagonistic muscles (semitendinosus-rectus femoris) was calculated using the following equation (27):

Co-contraction index $=($ lower SEMG $/$ higher SEMG $) \times($ lower SEMG + higher SEMG)

where the lower and higher SEMG represent the average RMSMVC value of the semitendinosus and rectus femoris muscles, respectively.

\section{Plasma sclerostin levels}

In a previous study on healthy young adult women, we determined that the plasma sclerostin (SOST) levels peaked at the $10^{\text {th }} \mathrm{min}$ after WBV (20). To standardise the change in plasma SOST levels occurring after vibration, the following formula was used:

SVI SOST index $=$ SOST level (10th minute after WBV) $/$ SOST level (before WBV).

Pre-trial sclerostin index and post-trial sclerostin index were calculated. To standardise the sclerostin index changes that occurred after the trial, the following formula was applied:

Sclerostin index change ratio $=$ post-trial sclerostin index $/$ pre-trial sclerostin index

The Standardized vibration Induced (SVI) SOST index was accepted as an indicator of the response of osteocytes to WBV. High plasma SOST levels were reported to indicate an increase in osteocyte activity (21). Thus, a high SVI SOST index was accepted as indicating an increase in osteocyte activity.

Blood samples were obtained before WBV and at the 10th minute after WBV in all participants. Blood samples were obtained by inserting an intravenous cannula into the antecubital vein. Blood was collected using EDTA and centrifuged for $15 \mathrm{~min}$ at 400x g within 15 min of collection. Aliquots of plasma were added to Eppendorf tubes and stored at $-80^{\circ} \mathrm{C}$.

Plasma sclerostin levels were measured blindly by the same researcher. Plasma sclerostin levels were measured using a Human Sclerostin ELISA kit $\left(\right.$ CUSABIO $^{\circledR}$ catalogue no: CSB-E13146h, Newark, DE, USA). All assays were performed according to the manufacturer's instructions. The minimum detectable concentration of human sclerostin is typically $<0.012 \mathrm{ng} . \mathrm{mL}-1$. None of the measured sclerostin values in our participants were below the limit of detection for this assay. Intra-assay precision was $<8 \%$.

\section{Bone mineral density}

Right-hip BMD was measured using NORLAND ${ }^{\circledR}$ (XR-46, Malvern, Pennsylvania, USA) DXA. Precision error was $<1.2 \%$ for hip BMD.

\section{Blinding}

All measurements were made by independent assessors blinded to the trial allocation. All participants were told that the WBV was performed for muscle strengthening. However, participants had no knowledge regarding the characteristics of the vibration used for muscle strength enhancement. WBV was performed in different sessions for the CON and EX groups so that each group was blind to the other's exposure.

\section{Statistical analyses}

Arithmetic mean and standard deviation (SD) were calculated for each variable assessed. All data were analysed for normal distribution using the Kolmogorov-Smirnov test. Comparison of the two groups was performed using an unpaired t-test for age, BMI, BMD, muscle strength, RMSMVC during quiet standing, NVI - RMS, and sclerostin index. Mann-Whitney $U$ test was applied to compare mean values of the co-contraction index between groups. A Wilcoxon test was applied to compare mean values of the co-contraction index within groups. The paired-samples t-test was used to analyse differences in muscle strength, sclerostin index, and NVI - RMS between pre-trial and post-trial measurements. Differences in the mean values and effect sizes with a $95 \%$ confidence interval (CI) are shown in the tables. Multiple linear regression (MLR) analysis was performed to detect independent predictors of changes in muscle strength and in NVI - RMS, and to determine confounding effects between potentially independent predictors. If the correlation coefficient $(\mathrm{R})$ between any independent variable (e.g., age, BMI, BMD, and sclerostin index change ratio) and a dependent variable was higher than 0.20 , then the independent variable was included in the MLR analysis. A stepwise method was used to construct MLR models. A variable was entered into the model if the probability of its score statistic was less than the entry value (0.05), and it was removed if the probability was greater than the removal value $(0.1)$.

A p-value of $<0.05$ was considered statistically significant. The software package used for data management was PASW Statistic 18.

\section{RESULTS}

Data from pre-trial measurements are presented in Table 2. Pre-trial measurements showed that the co-contraction index for the antagonist (m.semitendinosus-m.rectus femoris) muscles significantly increased during WBV compared with the quiet standing posture in both groups. This finding showed a much more prominent increase in semitendinosus muscle activity during WBV.

Muscle strength measurements at $60^{\circ} . \mathrm{s}^{-1}$ angular velocity showed a significant increase in the flexor muscle strength in both knees in the EX group. The increase in muscle strength was $23.9 \%$ in the right knee flexors $(\mathrm{p}=0.004)$ and $27.5 \%$ in the left knee flexors $(\mathrm{p}<0.0001)$. However, no significant change 
TABLE 2. Data from pre-trial measurements

\begin{tabular}{|c|c|c|c|c|}
\hline & & Exercise $(\mathrm{n}=17)$ & Control $(n=17)$ & $\mathrm{p}$ value \\
\hline \multirow{4}{*}{ Isokinetic muscle torque (N.m) } & Right knee flexors & $41.0 \pm 11.0$ & $44.2 \pm 10.3$ & 0.844 \\
\hline & Left knee flexors & $38.5 \pm 8.3$ & $43.8 \pm 11.4$ & 0.840 \\
\hline & Right knee extensors & $111.8 \pm 22.0$ & $113.1 \pm 16.8$ & 0.390 \\
\hline & Left knee extensors & $108.9 \pm 22.3$ & $107.5 \pm 17.0$ & 0.130 \\
\hline \multirow[t]{2}{*}{ RMSMVC during quiet standing (\%) } & Right $\mathrm{m}$. rectus femoris & $3.7 \pm 4.8$ & $3.5 \pm 4.5$ & 0.890 \\
\hline & Right $\mathrm{m}$. semitendinosus & $1.1 \pm 0.9$ & $1.2 \pm 0.9$ & 0.765 \\
\hline \multirow[t]{2}{*}{ Vibration-induced RMS $(\mu \mathrm{V})$} & Right m. rectus femoris & $14.0 \pm 8.9$ & $15.8 \pm 6.2$ & 0.500 \\
\hline & Right $\mathrm{m}$. semitendinosus & $14.1 \pm 10.4$ & $16.5 \pm 9.5$ & 0.492 \\
\hline \multirow[t]{2}{*}{ NVI - RMS (\%) } & Right m. rectus femoris & $7.6 \pm 5.2$ & $10.1 \pm 6.3$ & 0.203 \\
\hline & Right $\mathrm{m}$. semitendinosus & $5.5 \pm 3.9$ & $6.5 \pm 3.0$ & 0.407 \\
\hline \multirow[t]{2}{*}{ Co-contraction index (\%MVC) } & during quiet standing & $2.4 \pm 3.2$ & $3.6 \pm 7.6$ & 0.310 \\
\hline & during WBV & $18.8 \pm 25.5$ & $12.9 \pm 6.8$ & 0.502 \\
\hline \multirow[t]{3}{*}{ Right hip BMD (g.cm²) } & Femur neck & $0.946 \pm 0.101$ & $0.924 \pm 0.105$ & 0.539 \\
\hline & Trochanter & $0.755 \pm 0.112$ & $0.715 \pm 0.090$ & 0.258 \\
\hline & Total hip & $0.989 \pm 0.131$ & $0.956 \pm 0.151$ & 0.503 \\
\hline Plasma sclerostin level before WBV & (ng.mL $\left.L^{-1}\right)$ & $1.63 \pm 0.62$ & $1.18 \pm 0.12$ & 0.009 \\
\hline Sclerostin index & & $1.02 \pm 0.29$ & $0.94 \pm 0.09$ & 0.249 \\
\hline
\end{tabular}

Values are mean \pm standard deviation (SD)

TABLE 3. Main effects of whole-body vibration training program on isokinetic strength of the right (R) and left (L) knee muscles and the sclerostin index

\begin{tabular}{|c|c|c|c|c|c|c|c|}
\hline & \multirow[b]{2}{*}{ Groups } & \multicolumn{3}{|c|}{ Change to 4 weeks } & \multicolumn{3}{|c|}{$\begin{array}{l}\text { Difference between } \\
\text { Exercise and Control }\end{array}$} \\
\hline & & Mea & $5 \% \mathrm{CI})$ & $\mathrm{p}$ value & Effec & $95 \% \mathrm{CI})$ & $\mathrm{p}$ value \\
\hline \multirow[t]{2}{*}{ R flexors muscle strength } & Exercise & $29.0 \%$ & $(9.0$ to 48.9$)$ & 0.004 & $23.9 \%$ & (2.6 to 45.1$)$ & 0.029 \\
\hline & Control & $5.1 \%$ & $(-3.3$ to 13.5$)$ & 0.227 & & & \\
\hline \multirow[t]{2}{*}{ R extensors muscle strength } & Exercise & $2.2 \%$ & $(-7.1$ to 11.5$)$ & 0.831 & $2.6 \%$ & $(-10.6$ to 15.8$)$ & 0.686 \\
\hline & Control & $-0.5 \%$ & $(-10.6$ to 9.6$)$ & 0.381 & & & \\
\hline \multirow[t]{2}{*}{ L flexors muscle strength } & Exercise & $32.8 \%$ & $(19.2$ to 46.3$)$ & 0.000 & $27.5 \%$ & $(10.1$ to 44.9$)$ & 0.003 \\
\hline & Control & $5.3 \%$ & $(-6.8$ to 17.3$)$ & 0.381 & & & \\
\hline \multirow[t]{2}{*}{ L extensors muscle strength } & Exercise & $1.4 \%$ & $(-5.7$ to 8.4$)$ & 0.831 & $0.8 \%$ & $(-8.7$ to 10.2$)$ & 0.868 \\
\hline & Control & $0.6 \%$ & $(-6.2$ to 7.4$)$ & 0.906 & & & \\
\hline \multirow[t]{2}{*}{ Sclerostin index } & Exercise & $-15.2 \%$ & $(-27.8$ to -2.6$)$ & 0.031 & $-36.0 \%$ & $(-56.0$ to -15.9$)$ & 0.001 \\
\hline & Control & $20.8 \%$ & $(4.2$ to 37.5$)$ & 0.028 & & & \\
\hline
\end{tabular}

was observed in the extensor muscle strength in either knee. There was no significant change in the knee muscle strength in the CON group (Table 3). Muscle strength measurements at $180^{\circ} . \mathrm{s}-1$ and $240^{\circ} . \mathrm{s}^{-1}$ angular velocity showed a non-significant change in the flexor and extensor muscle strength in both groups (data not shown). The sclerostin index decreased by $15.2 \%(p=0.031)$ after completion of the 20 sessions of the exercise program in the EX group (Table 3 ).

Compared with the pre-trial WBV-2.set, the NVI - RMS of the semitendinosus muscle decreased by 2.8 times $(p=0.005)$ during post-trial WBV-1.set in the EX group (Table 4). However, there was no significant difference in the NVI - RMS of the semitendinosus muscle between the pre-trial 2.set data and post-trial 1.set data in the EX group (Table 5). A prominent peak in the vibration frequency was found in the filtered and rectified SEMG spectrograms of the knee muscles in all participants (Figure 4).
MLR analysis performed for the semitendinosus muscle indicated that a change in the sclerostin index was an important predictor of change in the NVI - $\mathrm{RMS}(\mathrm{R} 2=0.73, \mathrm{~F}=89.9, \mathrm{p}=0.0001$ for NVI-RMS change ratio- 1 and $\mathrm{R} 2=0.74, \mathrm{~F}=91.0, \mathrm{p}=0.0001$ for NVI-RMS change ratio-2). The positive regression coefficient (B) showed a positive correlation between change in the sclerostin index and change in the NVI - RMS. Additionally, femoral neck BMD was an important predictor of the muscle strength gain of the right knee flexor $\left(\mathrm{R}^{2}=0.26, \mathrm{~F}=5.3, \mathrm{p}=0.035\right)$. The negative regression coefficient (B) showed an inverse correlation between BMD and muscle strength gain (Table 6).

\section{DISCUSSION}

There are a number of original findings in this study. Firstly, an increase in muscle strength was detected, along with 
TABLE 4. Main effects of WBV training program on NVI - RMS of the $\mathrm{m}$. rectus femoris and $\mathrm{m}$. semitendinosus. Comparison of mean NVI - RMS between post-trial 1.set and pre-trial 2.set

\begin{tabular}{|c|c|c|c|c|c|c|c|}
\hline & \multirow[b]{2}{*}{ Groups } & \multicolumn{3}{|c|}{ Change to 4 weeks } & \multicolumn{3}{|c|}{$\begin{array}{l}\text { Difference between } \\
\text { Exercise and Control }\end{array}$} \\
\hline & & $\mathrm{Me}$ & CI) & $\mathrm{p}$ value & Eff & e $(95 \% \mathrm{CI})$ & $\mathrm{p}$-value \\
\hline \multirow[t]{2}{*}{ M. rectus femoris } & Exercise & -2.1 & $(-5.9$ to 1.8$)$ & 0.268 & 0.8 & $(-3.9$ to 5.4$)$ & 0.734 \\
\hline & Control & -2.9 & $(-5.8$ to 0.1$)$ & 0.059 & & & \\
\hline \multirow[t]{2}{*}{ M. semitendinosus } & Exercise & -2.8 & $(-4.6$ to -1.0$)$ & 0.005 & -3.9 & $(-6.3$ to -1.6$)$ & 0.002 \\
\hline & Control & 1.2 & $(-0.5$ to 2.9$)$ & 0.161 & & & \\
\hline
\end{tabular}

TABLE 5. Main effects of WBV training program for NVI - RMS of the $\mathrm{m}$. rectus femoris and $\mathrm{m}$. semitendinosus. Comparison of mean NVI - RMS between post-trial 2.set and pre-trial 2.set

\begin{tabular}{|c|c|c|c|c|c|c|c|}
\hline \multirow[b]{3}{*}{ M. rectus femoris } & \multirow{3}{*}{$\begin{array}{l}\text { Groups } \\
\text { Exercise }\end{array}$} & \multicolumn{3}{|c|}{ Change to 4 weeks } & \multicolumn{3}{|c|}{$\begin{array}{l}\text { Difference between } \\
\text { Exercise and Control }\end{array}$} \\
\hline & & \multicolumn{2}{|c|}{ Mean $(95 \% \mathrm{CI})$} & \multirow{2}{*}{$\begin{array}{c}\mathrm{p} \text { value } \\
0.804\end{array}$} & \multicolumn{2}{|c|}{ Effect Size $(95 \% \mathrm{CI})$} & \multirow{2}{*}{$\begin{array}{c}\mathrm{p} \text {-value } \\
0.239\end{array}$} \\
\hline & & -0.5 & (-4.4 to 3.5$)$ & & -3.6 & $(-9.8$ to 2.5$)$ & \\
\hline & Control & & 3.1 & $(-2.0$ to 8.3$)$ & 0.212 & & \\
\hline \multirow[t]{2}{*}{ M. semitendinosus } & Exercise & -1.8 & $(-3.6$ to 0.0$)$ & 0.053 & -6.3 & $(-9.0$ to -3.5$)$ & 0.0001 \\
\hline & Control & 4.5 & (2.3 to 6.8 ) & 0.001 & & & \\
\hline
\end{tabular}

TABLE 6. Multiple linear regression models for change in muscle strength of the right knee flexor and change in NVI - RMS of the right semitendinosus muscle

\begin{tabular}{|c|c|c|c|c|c|c|c|c|c|c|}
\hline \multirow{2}{*}{$\begin{array}{l}\text { Dependent } \\
\text { variable }\end{array}$} & \multirow{2}{*}{$\begin{array}{l}\text { Independent } \\
\text { variable }\end{array}$} & \multirow[b]{2}{*}{ R2 } & \multirow[b]{2}{*}{$\mathrm{F}$} & \multirow[b]{2}{*}{ df } & \multirow[b]{2}{*}{$\mathrm{p}$-value } & \multirow[b]{2}{*}{ DW } & \multicolumn{2}{|c|}{$\begin{array}{c}\text { Unstandardised } \\
\text { Coefficient }\end{array}$} & \multirow[b]{2}{*}{$\mathrm{t}$} & \multirow[b]{2}{*}{$\mathrm{p}$ value } \\
\hline & & & & & & & $\mathrm{B}$ & SE & & \\
\hline \multirow[t]{2}{*}{ Muscle strength gain } & Coefficient & 0.26 & 5.3 & 16 & 0.035 & 2.5 & 3.10 & 0.81 & 3.8 & 0.001 \\
\hline & Neck BMD & & & & & & -1.90 & 0.85 & -2.3 & 0.035 \\
\hline NVI - RMS CR-1 & SOST index CR & 0.73 & 89.9 & 33 & 0.0001 & 2.5 & 0.85 & 0.08 & 9.4 & 0.0001 \\
\hline NVI - RMS CR-2 & SOST index CR & 0.74 & 91.0 & 33 & 0.0001 & 2.0 & 1.26 & 0.13 & 9.5 & 0.0001 \\
\hline
\end{tabular}

SOST index CR: sclerostin index change ratio, NVI - RMS CR: NVI - RMS change ratio, DW: Durbin-Watson, df: degree of freedom, SE: standard error

changes in vibration-induced reflex activity upon completion of the WBV exercise program. In contrast to the case with progressive-resistance exercises, it is an important finding that muscle strength increased without any voluntary contractions. Secondly, changes had occurred in the sclerostin index (the response given by the bone to vibration) upon completion of the WBV exercise program. Thirdly, BMD was an important predictor of muscle strength gain, and changes in the response given by the bone to vibration was an important predictor of changes in vibration-induced reflex muscle activity with WBV exercise.

\section{Methodological approach to the problem}

Considering the overload principle, resistance exercises are often applied to healthy individuals when an increase in muscle strength is needed (28). Therefore, the squat or semi-squat position is preferred in WBV exercises performed to increase muscular performance in the lower extremities $(6,22)$. In such positions, the joints are exposed to a significant moment of force due to gravity. To maintain a squat or semi-squat position, muscle contractions strong enough to overcome gravi- tational moments are required. Accelerated motion occurring during WBV causes gravity to fluctuate (micro gravity - hyper gravity). As a result, the joints are exposed to a higher moment of force during WBV. The higher the moment, the stronger the muscle contractions.

To analyse the effects of bone exposed to vibration on the increase in muscle strength, it is important to avoid voluntary muscle contractions. With that in mind, participants were trained on relaxation and appropriate posture techniques. Participants were asked to stand in an upright posture to minimise exposure to probable moment in lower extremity joints during WBV and to prevent resulting muscle contractions. However, it is difficult to maintain postural balance during WBV. An unstable posture triggers postural control mechanisms including muscle contractions to avoid loss of balance during WBV. According to the laws of physics, an object is in balance if its centre and line of gravity are above its base of support (29). Two precautions were taken to maintain postural stability during WBV. The base of support was adjusted, and the participants were asked to hold the front handle of the WBV device during WBV exercises. The results showed an increase 
in muscle strength of knee flexors without voluntary contractions. If the increase in muscle activity during WBV was primarily due to postural control mechanisms or voluntary muscle contraction, then the frequency of the SEMG signal would occur randomly throughout the power spectrum (5). However, as shown in Figure 4, frequency spectrograms of the SEMG signal recorded during WBV displayed a prominent peak at the vibration frequency in the present study. The emergence of this peak was attributed to the increase in motor unit activity synchronised with vibration frequency $(5,26)$.

\section{Possible mechanisms underlying vibration-induced reflex muscle activity}

The most frequently cited mechanism by which WBV increases muscle activity is the TVR, although there is no conclusive evidence that this occurs $(5,6)$. Muscle spindles are highly sensitive to cyclic mechanical stimulation (30). During WBV, all muscles are vibrated simultaneously (5). Therefore, muscle spindles in both knee extensors and flexors are exposed to cyclic mechanical stimulus during WBV exercises. It is possible to expect increased strength in both muscle groups after WBV exercises under such conditions. However, increases in muscle strength were detected only in knee flexors in the present study. It is difficult to explain such an increase in strength in an isolated muscle group with the help of TVR. Does BMR explain the increase in muscle strength observed solely in the knee flexors?

BMR regulates muscle activity by enabling the bone to be placed in the most appropriate position to carry the mechanical load to which it is exposed; the mechanical load should be well balanced for preserving the structural integrity of the bone. When the mechanical load is intensified in a cross-sectional area of the bone, osteocytes within that area are more exposed to the mechanical stimulus. BMR activates the muscles that could eliminate such asymmetrical loading. As a result, optimal distribution of the mechanical load through the bone is provided $(11,15,16)$.

Extension moment occurs in the knee joint in a quiet standing position (31). This is due to the line of gravity that extends in a line posterior to the hip joints but anterior to the knee and ankle joints (32). WBV applied in a quiet standing position leads to hyper gravity and increases the extension moment of the associated knee joint. As ligaments of the knee joint do not permit hyperextension, increasing the extension moment occurring during WBV could theoretically cause intensified mechanical loading in the anterior part of the cross-sectional area of the femur. This could also lead to compression within that area. Osteocytes within the region of the bone where compression increases occur are exposed to much stronger mechanical stimulation (19). The extension moment, which increases during WBV, can only be eliminated with the help of knee flexors. Thus, BMR can activate knee flexors to elimi- nate an unbalanced load distribution in the bone. A high extension moment in knee joints was reported to emerge together with increased semitendinosus muscle activity in a previous study (33). In our study, the pre-trial co-contraction index for the antagonist (m.semitendinosus-m.rectus femoris) muscles calculated for the quiet standing posture showed a much more prominent increase in semitendinosus muscle activity during WBV. This finding could explain the observation of increased strength in only the semitendinosus muscle.

Our study suggests that femoral neck BMD is an important predictor of the observed increase in knee flexor muscle strength. This study was carried out in healthy young adult women with normal BMD values. Further increases were detected in the muscle strength of the participants with a relatively low value of femoral neck BMD. Similar results were also reported in healthy young adult male participants exposed to electrical muscle stimulation on their wrist flexors simultaneously with passive wrist extension exercises (stimulated eccentric contraction exercises) for 20 sessions. It was reported that stimulated eccentric contraction exercises performed without voluntary muscle contractions caused an increase in wrist muscle strength. Ultradistal radius BMD was responsible for a $29.8 \%$ increase in strength (15). In the present study, WBV exercises led to a $26.3 \%$ increase in knee flexor muscle strength without voluntary contractions, which was attributable to femoral neck BMD.

The additional increase in muscle strength in cases with relatively low BMD is explained by biomechanical and structural features of osteocytic lacunas, which act as strain concentrators, effectively amplifying the macroscopic strain applied to the whole bone. This amplification is a function of the material properties of local perilacunar bone tissue. The stiff perilacunar bone tissue may attenuate the strain signal acting on embedded osteocytes. Conversely, the less mineralised bone region around each osteocyte may serve as an important strain amplifier. In participants with relatively low BMD, the perilacunar tissue should exhibit a lower perilacunar tissue modulus such that the available skeletal loads are converted to higher tissue strains at the lacuna. Thus, in participants with relatively low BMD, the less mineralised perilacunar bone may enhance the mechanical signal sensed by osteocytes and the activity of motoneurons $(15,34)$.

\section{Muscular adaptation to vibration stimuli}

Whole-body vibration exercises caused changes in the amplitude of vibration-induced reflex muscle activity (vibrationinduced RMS). Such changes were observed only in the EX group and only in the semitendinosus muscle. In both groups, low-amplitude ( $2 \mathrm{~mm}$ ) vibration was applied at pre-trial measurements. After the WBV exercise program was completed, low-amplitude vibration during the first set and high-amplitude $(4 \mathrm{~mm})$ vibration during the second set of post-trial mea- 
surements was applied. Compared with the pre-trial measurement, the mean amplitude of vibration-induced RMS did not change in the first set of post-trial measurements, whereas it increased in the second set in the CON group. CON participants were exposed to high-amplitude vibration only in the post-trial measurements. A stronger vibration stimulus led to a stronger reflex myoelectrical response (35). Consequently, low-magnitude WBV exercises did not cause a change in vibration-induced reflex muscle activity. However, in the EX group, high-magnitude WBV exercises were applied. Compared with the pre-trial measurement, the mean amplitude of NVI - RMS decreased in the first set of the post-trial measurements, whereas it did not change in the second set in the EX group. These findings may be explained by adaptation to high-intensity exercise. One such adaptation mechanism is proposed in the muscular wisdom hypothesis.

The muscular wisdom hypothesis proposes that the reduced motor-unit discharge rate during sustained maximal isometric contractions serves to minimise fatigue (36). Decreases in the motor-unit firing frequency could lead to a decrease in the amplitude of myoelectrical activity (RMS) (37). In our study, muscle activity during WBV was $5.5-10.1 \%$ of the MVC. Therefore, muscular wisdom does explain adaptation of the muscular response to WBV.

Another potential adaptation mechanism may be BMR. The BMR suggests that osteocytes exposed to vibration regulate muscle activities through neurological pathways. The muscle reflex response to vibration stimuli was assessed by NVI RMS in this study. The response of osteocytes to vibration stimuli was assessed by the sclerostin index. MLR analysis showed that the response of osteocytes to the vibration stimulus was an important predictor of the reflex response of the semitendinosus muscle to the vibration stimulus. Specifically, as the response given by osteocytes to the vibration decreased, muscle activity during the vibration decreased as well. The response of bone to the vibration stimulus (sclerostin index) decreased significantly after completion of the 20 sessions of the exercise program in the EX group. Thus, the results of this study may explain the muscular adaptation observed in the EX group. They also indicate the effects of osteocytes on reflex muscle activity during vibrations.

\section{Effects of whole-body vibration on plasma sclerostin levels}

Vibrations may have two types of effects on sclerostin, a mechanosensitive protein. First, vibrations decrease the production of sclerostin in osteocytes (19). WBV can change plasma sclerostin levels. The sclerostin index increases in accordance with the levels of sclerostin, which enters the systemic circulation from bony tissue with one session of WBV. However, the sclerostin index decreases when WBV is applied in consecutive sessions and with increasing intensity (20). Similar results were found in the present study. Decreases in the sclerostin index was detected in the EX group, which was exposed to progressively increasing vibrations. The mechanism that caused such a decrease is not yet known. However, the sclerostin index increased in the CON group, in which low-magnitude WBV was applied. CON participants were exposed to high-amplitude WBV for the first time during the final test measurements. During vibration, tissue blood flow and periosteocytic lacuna-canalicular fluid flow increased (6, 38). Therefore, more sclerostin may enter the blood circulation when a stronger vibration is applied.

\section{Limitations of this study}

This study has two main assumptions: the number of osteocytes in healthy young adults correlates with BMD and changes in plasma sclerostin levels during WBV indicate the response of osteocytes to vibration (receptor activity). As a general physiological principle, the number of receptors and their activities are important in the emergence of reflex activity (39). The 'receptor' of BMR is the osteocyte (15). Bone cells are composed of osteocytes (90-95\%). Osteocytes form a wide cellular network in the bone matrix. They are derived from osteoblasts, which are responsible for the formation of bone matrices. Osteocytes regulate matrix mineralisation during the bone-formation process. Osteocytes possess mechanosensitive features and the ability to reform the matrix structure of the bone microenvironment in accordance with exposure to mechanical stimulations (40). For these reasons, it was assumed that the number of osteocytes in healthy young adults would be correlated with BMD.

In the present study, the response of osteocytes to vibration stimuli was evaluated by means of plasma sclerostin levels, because sclerostin is produced almost exclusively by osteocytes. Additionally, sclerostin expression is regulated by mechanical strain in adult bone, and plasma sclerostin levels increase after WBV (17-20). High plasma sclerostin levels were reported to indicate an increase in osteocyte activity (21). These reports constituted a basis for the second assumption of our study.

In conclusion, this study indicates that bone tissue may have an effect on vibration-induced muscle strength gain and vibration-induced reflex muscle activity. This is the first study showing increased muscle strength without voluntary contractions using WBV exercise.

Knowledge of the effects of bone tissue on muscle performance may be important for exercise physiology programs designed to promote a healthy body and in rehabilitation programs. In this respect, bone quality is very important. For rehabilitation patients, preventing bone loss due to immobilisation or disability may be important for preventing loss of muscle strength and success of rehabilitation therapy. Applying vibration to bone may be sufficient to prevent loss of muscle strength. To achieve this, voluntary contraction is not required. For athletes, high bone quality may be important 
for achieving high muscular performance. The growing years provide a valuable window of opportunity for building high bone quality. In developing elite athletes, it is possible that measures could be taken to achieve high bone quality during childhood and adolescence.

Ethics Committee Approval: Ethics committee approval was received for this study from the Ethics Committee of İstanbul University İstanbul Medical Faculty (Approval Number: 2011/392-461).

Informed Consent: Informed consent was obtained from participants of this study.

Peer-review: Externally peer-reviewed.

Author contributions: Concept - İ.K.; Design - i.K., M.C., D.D., A.Y., S.H.K., M.U., K.G., M.Ö., S.S.K.; Supervision - İ.K.; Resource - İ.K., M.C., S.S.K., D.D., S.H.K.; Materials - İ.K., M.C., S.H.K.; Data Collection\&/or Processing - İ.K., M.C., D.D., A.Y., S.H.K., M.U., K.G., M.Ö.; Analysis\&/ or Interpretation - İ.K., M.C., D.D., A.Y., S.H.K., M.U., K.G., M.Ö., S.S.K.; Literature Search - İ.K.; Writing - İ.K., M.C., D.D., A.Y., S.H.K., M.U., K.G., M.Ö., S.S.K.; Critical Reviews - İ.K., M.C., D.D., A.Y., S.H.K., M.U., K.G., M.Ö., S.S.K.

Conflict of Interest: No conflict of interest was declared by the authors.

Financial Disclosure: This study is supported by a grant (BEAH20110002) from Bağcclar Training and Research Hospital Scientific Fund.

\section{REFERENCES}

1. Cochrane DJ. Vibration exercise: the potential benefits. Int J Sports Med 2011;32:75-99. [CrossRef]

2. Delecluse C, Roelants M, Verschueren S. Strength increase after wholebody vibration compared with resistance training. Med Sci Sports Exerc 2003;35:1033-41. [CrossRef]

3. Di Giminiani R, Manno R, Scrimaglio R, Sementilli S, Tihanyi J. Effects of individualized whole-body vibration on muscle flexibility and mechanical power. J Sports Med Phys Fitness 2010;50:139-51.

4. Wilcock IM, Whatman C, Harris N, Keogh JW. Vibration training:could it enhance the strength, power, or speed of athletes? J Strength Cond Res 2009;23:593-603.

5. Pollock RD, Woledge RC, Martin FC, Newham DJ. Effects of whole body vibration on motor unit recruitment and threshold. J Appl Physiol 2012;112:388-95. [CrossRef]

6. Rittweger J. Vibration as an exercise modality: how it may work, and what its potential might be. Eur J Appl Physiol 2010;108:877-904. [CrossRef]

7. Martin BJ, Park HS. Analysis of the tonic vibration reflex:influence of vibration variables on motor unit synchronization and fatigue. Eur $J$ Appl Physiol Occup Physiol 1997;75:504-11. [CrossRef]

8. Dindar F, Verrier M. Studies on the receptor responsible for vibration induced inhibition of monosynaptic reflexes in man. J Neurol Neurosurg Psychiatry 1975;38:155-60. [CrossRef]

9. Ekblom MM, Thorstensson A. Effects of prolonged vibration on Hreflexes muscle activation and dynamic strength. Med Sci Sports Exerc 2011;43:1933-9. [CrossRef]

10. Hopkins JT, Fredericks D, Guyon PW, Parker S, Gage M, Feland JB, et al. Whole body vibration does not potentiate the stretch reflex. Int $J$ Sports Med 2009;30:124-9. [CrossRef]
11. Karacan I, Sariyildiz MA, Bahadir C, Ozen A. Effect of bone tissue on vibration-induced electrical activity of muscles. Turkiye Klinikleri $J$ Med Sci 2010;30:1346-56. [CrossRef]

12. Kipp K, Johnson ST, Doeringer JR, Hoffman MA. Spinal reflex excitability and homosynaptic depression after a bout of whole-body vibration. Muscle Nerve 2011;43:259-62. [CrossRef]

13. Ribot-Ciscar E, Rossi-Durand C, Roll JP. Muscle spindle activity following muscle tendon vibration in man. Neurosci Lett 1998;24:147-50. [CrossRef]

14. Ritzmann R, Kramer A, Gollhofer A, Taube W. The effect of whole body vibration on the H-reflex, the stretch reflex, and the short-latency response during hopping. Scand J Med Sci Sports 2013;23:331-9. [CrossRef]

15. Karacan I, Sariyildiz MA, Ergin O, Ozen A, Karamehmetoglu SS. Bone myoregulation reflex: a possible new mechanism. Nobel Med 2009;5:9-17.

16. Karacan I, Cidem M, Bahadir C, Rezvani A, Ozen A, Unalan HI. The effect of bone mineral density of distal radius exposed to vibration on rest activity of contralateral wrist flexor. Turkiye Klinikleri J Med Sci 2012;32:1673-80. [CrossRef]

17. Gaudio A, Pennisi P, Bratengeier C, Torrisi V, Lindner B, Mangiafico $\mathrm{RA}$, et al. Increased sclerostin serum levels associated with bone formation and resorption markers in patients with immobilization-induced bone loss. J Clin Endocrinol Metab 2010;95:2248-53. [CrossRef]

18. Lombardi G, Lanteri P, Colombini A, Mariotti M, Banfi G. Sclerostin concentrations in athletes:role of load and gender. J Biol Regul Homeost Agents 2012;26:157-63.

19. Robling AG, Niziolek PJ, Baldridge LA, Condon KW, Allen MR, Alam I, et al. Mechanical stimulation of bone in vivo reduces osteocyte expression of Sost/sclerostin. J Biol Chem 2008;29:5866-75.

20. Çidem M, Karakoç Y, Ekmekçi H, Küçük SH, Uludağ M, Gün K, et al. Effects of whole body vibration on plasma sclerostin level in healthy women. Turk J Med Sci DOI: 10.3906/sag-1302-88. [CrossRef]

21. Voskaridou E, Christoulas D, Plata E, Bratengeier C, Anastasilakis A, Komninaka V, et al. High circulating sclerostin is present in patients with thalassemia-associated osteoporosis and correlates with bone mineral density. Horm Metab Res 2012;44:909-13. [CrossRef]

22. Ritzmann R, Gollhofer A, Kramer A. The influence of vibration type, frequency, body position and additional load on the neuromuscular activity during whole body vibration. Eur J Appl Physiol 2013;113:1-11. [CrossRef]

23. Hermens HJ, Freriks B, Disselhorst-Klug C, Rau G. Development of recommendations for SEMG sensors and sensor placement procedures. J Electromyogr Kinesiol 2000;10:361-74. [CrossRef]

24. Abercromby AF, Amonette WE, Layne CS, McFarlin BK, Hinman MR, Paloski WH. Variation in neuromuscular responses during acute whole-body vibration exercise. Med Sci Sports Exerc 2007;39:1642-50. [CrossRef]

25. Fratini A, Cesarelli M, Bifulco P, Romano M. Relevance of motion artifact in electromyography recordings during vibration treatment. $J$ Electromyogr Kinesiol 2009;19:710-8. [CrossRef]

26. Sebik O, Karacan I, Cidem M, Turker K. Rectification of SEMG as a tool to demonstrate synchronous motor unit activity during vibration. $J$ Electromyogr Kinesiol 2013;23:275-84. [CrossRef]

27. Rudolph KS, Axe MJ, Buchanan TS, Scholz JP, Snyder-Mackler L. Dynamic stability in the anterior cruciate ligament deficient knee. Knee Surg Sports Traumatol Arthrosc 2001;9:62-71. [CrossRef]

28. Hart JM, Fowler DE, Lunardini DJ. Exercise Physiology. In: Jesse C, Drez DD, Miller MD, editors. Orthopaedic Sports Medicine: Principles and Practice. Saunders \& Elsevier Philadelphia;2010:207-20.

29. Lugade V, Lin V, Chou LS. Center of mass and base of support interaction during gait. Gait Posture 2011;33:406-11. [CrossRef]

30. Brown MC, Engberg I, Matthews PB. The relative sensitivity to vibration of muscle receptors of the cat. J Physiol 1967;192:773-800.

31. Beynnon B, Johnson RJ, Brown L. Relevant Biomechanics of the Knee. In:Jesse C, Drez DD, Miller MD, editors. Orthopaedic Sports Medicine: Principles and Practice. Saunders \& Elsevier Philadelphia;2010:1579-95. 
32. Dangelo MD, Grieve DW, Pereira LF, Watkinson T. A description of normal relaxed standing postures. Clinical Biomechanics 1987;2:140-144. [CrossRef]

33. Greenwood NL, Duffell LD, Alexander CM, McGregor AH. Electromyographic activity of pelvic and lower limb muscles during postural tasks in people with benign joint hypermobility syndrome and non hypermobile people. A pilot study. Man Ther 2011;16:623-8. [CrossRef]

34. Bonivtch AR, Bonewald LF, Nicolella DP. Tissue strain amplification at the osteocyte lacuna: a microstructural finite element analysis. J Biomech 2007;40:2199-206. [CrossRef]

35. Pollock RD, Woledge RC, Mills KR, Martin FC, Newham DJ. Muscle activity and acceleration during whole body vibration: effect of frequency and amplitude. Clin Biomech (Bristol, Avon) 2010;25:840-6. [CrossRef]
36. Fuglevand AJ, Keen DA. Re-evaluation of muscle wisdom in the human adductor pollicis using physiological rates of stimulation. J Physiol 2003;549:865-75. [CrossRef]

37. Kallenberg LA, Hermens HJ. Behaviour of motor unit action potential rate,estimated from surface EMG, as a measure of muscle activation level. J Neuroeng Rehabil 2006;3:15. [CrossRef]

38. Duncan RL, Turner $\mathrm{CH}$. Mechanotransduction and the functional response of bone to mechanical strain. Calcif Tissue Int 1995;57:344-58. [CrossRef]

39. Hall JE. Textbook of Medical Physiology. Saunders Elsevier. Philadelphia; 2011.

40. Georg Schett. Biology Physiology and Morphology of Bone. In: Firestein GS, Budd RC, Gabriel SE, McInnes LB, O’Dell JR, editors. Kelley's Textbook of Rheumatology. Saunders an imprint of Elsevier Inc; 2013:61-68. 